\title{
Redox-Reaction Based Spectrophotometric Assay of Isoniazid in Pharmaceuticals
}

\author{
N. Swamy, K. N. Prashanth, and K. Basavaiah \\ Department of Studies in Chemistry, University of Mysore, Manasagangotri, Mysore 570 006, India \\ Correspondence should be addressed to K. Basavaiah; kanakapurabasavaiah@gmail.com
}

Received 21 January 2014; Accepted 25 February 2014; Published 22 April 2014

Academic Editors: B. N. Barman, G. Drochioiu, J. V. Garcia Mateo, B. Rittich, and A. Szemik-Hojniak

Copyright (C) 2014 N. Swamy et al. This is an open access article distributed under the Creative Commons Attribution License, which permits unrestricted use, distribution, and reproduction in any medium, provided the original work is properly cited.

Two spectrophotometric methods are described for the determination of isoniazid (INH) in pharmaceuticals. In the first method (FCR method), INH is reacted with Folin-Ciocalteu reagent in $\mathrm{Na}_{2} \mathrm{CO}_{3}$ medium and the resulting blue colored chromogen measured at $760 \mathrm{~nm}$. Iron(II), formed as a result of reaction between INH and iron(III), is made to react with ferricyanide, and the resulting Prussian blue is measured at $760 \mathrm{~nm}$, basing the second method (FFC method). The conditions for better performance are optimized. Beer's law is obeyed in the concentration ranges $0.5-10$ and $0.2-3.0 \mu \mathrm{g} \mathrm{mL}^{-1}$ for FCR method and FFC methods, respectively, with corresponding molar absorptivity values of $1.12 \times 10^{4}$ and $4.55 \times 10^{4} \mathrm{~L} \mathrm{~mol}^{-1} \mathrm{~cm}^{-1}$. The methods are validated for accuracy, precision, LOD, LOQ, robustness, and ruggedness as per the current ICH guidelines. The validated methods were successfully applied to quantify INH in its commercial formulation with satisfactory results; hence the methods are suitable for isoniazid determination in bulk drugs and pharmaceuticals.

\section{Introduction}

Isoniazid (INH) (Figure 1), chemically known as pyridine4-carboxylic acid hydrazide, is an antitubercular drug now widely used together with rifampicin and streptomycin for the chemotherapy of tuberculosis. This has prompted many investigators to devise methods for its determination in its pure form as well as in its tablet form.

The drug is official in Indian Pharmacopoeia (IP) [1], British Pharmacopoeia (BP) [2], and United State Pharmacopoeia (USP) [3]. IP and BP describe titration of the drug with potassium bromate in presence of potassium bromide using methyl red indicator. USP describes HPLC method using $\mathrm{L}_{1}$ column $(4.6 \mathrm{~mm} \times 25 \mathrm{~cm})$ and a mobile phase consisting of methanol: water $(40: 60)(\mathrm{pH}$ adjusted to 2.5 with $\mathrm{H}_{2} \mathrm{SO}_{4}$ ) with a flow rate of $1.5 \mathrm{~mL} \mathrm{~min}^{-1}$ and UVdetection at $254 \mathrm{~nm}$. Apart from the above official methods, a number of methods based on several techniques are found in the literature for INH and include titrimetry [4-7], voltammetry [8-13], ion selective electrode-potentiometry [14-19], amperometry [20, 21], spectrofluorimetry [22, 23], chemiluminescence spectrometry [24-33], high performance liquid chromatography (HPLC) [34-37], gas chromatography (GC) [38-40], LC/LC-MS [41], and capillary electrophoresis [42-44].

Visible spectrophotometry is by far the most widely used technique for the assay of INH. Methods were based on a variety of reaction schemes such as nucleophilic substitution [45], condensation [46-49], charge-transfer and ionpair [50], derivatization [51-54], diazo-coupling [55, 56], oxidative coupling $[57,58]$, complex formation [59-61], and redox followed by complexation [62-65]. These methods suffer from one or more of the disadvantages such as drastic experimental conditions, use of organic solvent, longer standing time, poor sensitivity, and narrow linear range. Folin-Ciocalteu (F-C) reagent or iron(III) and ferricyanide have been widely used for the sensitive determination of a wide-ranging phenolic and amine organic compounds of pharmaceutical importance [66-74].

The aim of this work was to investigate the utility of F-C reagent and iron(III) and ferricyanide systems in the assay of INH. The methods had sufficiently good accuracy and precision and presented a simple and time-saving assay of INH. 


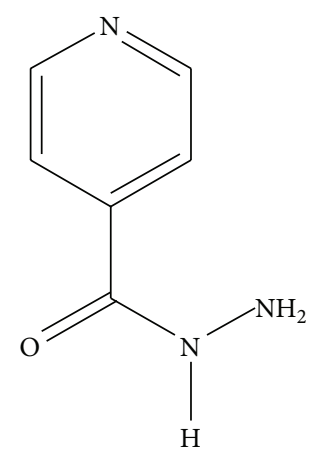

FIGURE 1: Structure of INH.

\section{Experimental}

2.1. Apparatus. A Systronics model 166 digital spectrophotometer (Ahmedabad, India) with matched 1-cm quartz cells was used for absorbance measurements.

\section{Materials}

Chemicals used were of analytical reagent grade. Distilled water was used throughout the investigation. Pharmaceutical grade INH certified to be $99.85 \%$ pure was kindly provided by Cipla India Ltd., Bangalore, India, and was used as received. Isokin-300 (Pfizer Ltd., Gandhinagar, Hyderabad, India) tablets containing isoniazid $300 \mathrm{mg}$ with vitamin $\mathrm{B}_{6}$ $10 \mathrm{mg}$ were purchased from local commercial store.

\subsection{Reagents}

3.1.1. Folin-Ciocalteu Reagent. Aqueous solution of FolinCiocalteu reagent $(1: 1 \mathrm{v} / \mathrm{v})$ was prepared by mixing $50 \mathrm{~mL}$ of reagent (Merck, Mumbai, India) with $50 \mathrm{~mL}$ water.

3.1.2. Sodium Carbonate. A $20 \%$ solution of sodium carbonate was prepared by dissolving $20 \mathrm{~g}$ compound (S.D. Fine Chem. Ltd., Mumbai, India) in $100 \mathrm{~mL}$ water.

3.1.3. Potassium Ferricyanide. A $500 \mu \mathrm{g} \mathrm{mL}^{-1}$ potassium ferricyanide solution was prepared by dissolving $50 \mathrm{mg}$ reagent (Glaxo Laboratory, Mumbai, India) in $100 \mathrm{~mL}$ water.

3.1.4. Ferric Chloride $\left(\mathrm{FeCl}_{3}\right)$. A solution of $0.5 \mathrm{M}$ $\mathrm{FeCl}_{3} \cdot 6 \mathrm{H}_{2} \mathrm{O}$ was prepared by dissolving $14 \mathrm{~g}$ of the chemical (S.D. Fine Chem. Ltd., Mumbai, India) in $100 \mathrm{~mL}$ of $0.1 \mathrm{M}$ $\mathrm{HCl}$ (Merck, Mumbai, India).

3.1.5. Standard Drug Solution. A stock standard solution of INH $\left(100 \mu \mathrm{g} \mathrm{mL}^{-1}\right)$ was prepared by dissolving $10 \mathrm{mg}$ of pure INH in $100 \mathrm{~mL}$ water, appropriately diluted to $20 \mu \mathrm{g} \mathrm{mL}^{-1}$ INH for method A and $10 \mu \mathrm{g} \mathrm{mL}^{-1}$ INH for method B with water, and used in the assay.

\section{Assay Procedure}

4.1. Method A (FCR Method). Into a series of $10 \mathrm{~mL}$ volumetric flasks, different aliquots of working standard INH solution $\left(20 \mu \mathrm{g} \mathrm{mL}^{-1}\right)$ ranging from 0.25 to $5.0 \mathrm{~mL}$ equivalent to $0.5-10.0 \mu \mathrm{g} \mathrm{mL}^{-1}$ were transferred and the total volume was brought to $5 \mathrm{~mL}$ with water. To each flask, $2 \mathrm{~mL}$ of 1:1 F-C reagent and $2 \mathrm{~mL}$ of $20 \% \mathrm{Na}_{2} \mathrm{CO}_{3}$ solution were successively added by means of a microburette. The flasks were stoppered and the contents were mixed well and kept at room temperature for $10 \mathrm{~min}$. The volume was made up to the mark with water and the absorbance of each solution was measured at $760 \mathrm{~nm}$ against a reagent blank similarly prepared in the absence of INH.

4.2. Method B (FFC Method). Different aliquots of standard INH solution $\left(10 \mu \mathrm{g} \mathrm{mL}^{-1}\right)$ ranging from 0.2 to $3.0 \mathrm{~mL}$ were transferred into a series of $10 \mathrm{~mL}$ of calibrated flasks and the total volume was brought to $3 \mathrm{~mL}$ with water. Then, $1.5 \mathrm{~mL}$ of $500 \mu \mathrm{g} \mathrm{mL}^{-1}$ potassium ferricyanide and $1.0 \mathrm{~mL}$ $\mathrm{FeCl}_{3}$ solution were accurately added. The volume was made up to the mark with water, content mixed, and the flasks were kept at room temperature. After $10 \mathrm{~min}$, the absorbance was measured at $760 \mathrm{~nm}$ against reagent blank prepared simultaneously without adding INH.

Standard graph was prepared by plotting the absorbance versus INH concentration, and the concentration of the unknown was computed from the respective regression equation derived using the absorbance-concentration data.

4.3. Procedure for Pharmaceutical Tablets. Twenty tablets were weighed and ground into a fine powder. An accurately weighed quantity containing $10 \mathrm{mg}$ of INH was transferred to a $100 \mathrm{~mL}$ volumetric flask, $60 \mathrm{~mL}$ water added, shaken well for 20 minutes and made up to mark with water, and then filtered. This solution was diluted to a 20 and $10 \mu \mathrm{g} \mathrm{mL}^{-1} \mathrm{INH}$ with water and analyzed by the recommended procedures.

4.4. Procedure for Placebo Blank and Synthetic Mixture Analyses. A placebo blank containing starch (10 mg), acacia (15 mg), hydroxyl cellulose (10 mg), sodium citrate $(10 \mathrm{mg})$, talc $(20 \mathrm{mg})$, magnesium stearate $(15 \mathrm{mg})$, and sodium alginate $(10 \mathrm{mg})$ was prepared by mixing all components into a homogeneous mixture. $10 \mathrm{mg}$ of the placebo blank was accurately weighed and its solution was prepared as described under Procedure for Pharmaceutical Tablets and then subjected to analysis by following the general procedure.

An accurately weighed $10 \mathrm{mg}$ of INH was added to $10 \mathrm{mg}$ of placebo blank and homogenized. Synthetic mixture was quantitatively transferred into a $100 \mathrm{~mL}$ volumetric flask and the extract was prepared as described under the Procedure for Pharmaceutical Tablets. The resulting extract was diluted to get 20 and $10 \mu \mathrm{g} \mathrm{mL}^{-1}$ INH solutions, respectively. Suitable aliquot of the solution was analyzed at three levels by following the general assay procedure. 


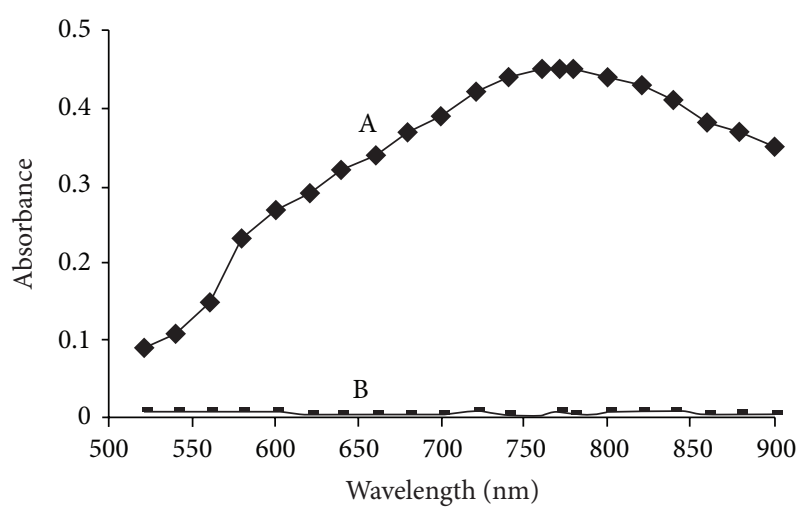

(a)

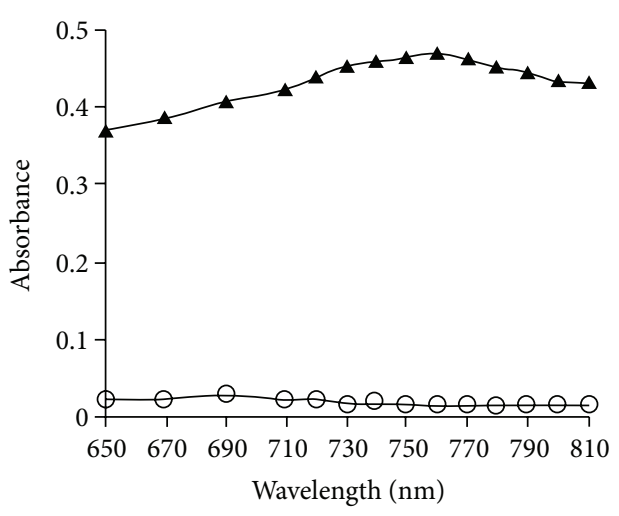

(b)

FIGURE 2: (a) Absorption spectra of A: reaction product of INH $\left(6 \mu \mathrm{g} \mathrm{mL} L^{-1}\right)$ with F-C reagent in $\mathrm{Na}_{2} \mathrm{CO}_{3}$ solution and B: blank. (b) Absorption spectra for method B, reaction product of INH $\left(1.25 \mu \mathrm{g} \mathrm{mL}{ }^{-1}\right)$ with ferric chloride and ferricyanide solution (- - -) and blank (-Î§-).

\section{Validation of Method}

The method was validated according to the procedures described in ICH guidelines [75] for the validation of analytical methods.

Limits of Detection (LOD) and Quantification (LOQ). The limits of detection (LOD) and quantification (LOQ) were calculated according to the ICH guidelines using the formulae:

$$
\text { LOD }=3.3 \frac{S}{b}, \quad L O Q=10 \frac{S}{b},
$$

where $S$ is the standard deviation of blank absorbance values and $b$ is the slope of the calibration plot.

5.1. Precision and Accuracy. The intraday precision was evaluated by analyzing INH solution at three different levels. Similarly the interday precision was evaluated on five consecutive days $(n=5)$. In each case and for each concentration, mean value of the INH found and the relative standard deviations (RSD) were calculated. The accuracy of the methods was determined by the percent mean deviation between the obtained and known concentration of INH.

5.2. Robustness and Ruggedness. Method robustness was studied by making small changes in the optimized experimental variables and their effect on the absorbance was evaluated by calculating the percentage RSD values. In order to determine the method ruggedness, analyses were performed using three instruments and also by three analysts with the same instrument.

\section{Results and Discussion}

The proposed FCR method is based on the formation of a blue colored chromogen, following the reduction of phosphomolybdotungstic mixed acid of the F-C reagent [73] by INH in the presence of sodium carbonate, which could be measured at $760 \mathrm{~nm}$. The mixed acids in the $\mathrm{F}-\mathrm{C}$ reagent
TABLE 1: Sensitivity and regression parameters.

\begin{tabular}{|c|c|c|}
\hline Parameter & Method A & Method B \\
\hline$\lambda_{\max }, \mathrm{nm}$ & 760 & 760 \\
\hline Color stability, min & 60 & 90 \\
\hline Linear range, $\mu \mathrm{g} \mathrm{mL}^{-1}$ & $0.5-10.0$ & $0.2-3.0$ \\
\hline Molar absorptivity $(\varepsilon), \mathrm{L} \mathrm{mol}^{-1} \mathrm{~cm}^{-1}$ & $1.12 \times 10^{4}$ & $4.55 \times 10^{4}$ \\
\hline Sandell sensitivity ${ }^{*}, \mu \mathrm{g} \mathrm{cm}^{-2}$ & 0.0123 & 0.003 \\
\hline Limit of detection (LOD), $\mu \mathrm{g} \mathrm{mL}^{-1}$ & 0.03 & 0.14 \\
\hline Limit of quantification (LOQ), $\mu \mathrm{g} \mathrm{mL}^{-1}$ & 0.09 & 0.42 \\
\hline \multicolumn{3}{|l|}{ Regression equation, $Y^{* *}$} \\
\hline Intercept $(a)$ & 0.0131 & 0.0198 \\
\hline Slope $(b)$ & 0.0905 & 0.3176 \\
\hline Standard deviation of $a\left(S_{a}\right)$ & $9.98 \times 10^{-2}$ & $9.98 \times 10^{-2}$ \\
\hline Standard deviation of $b\left(S_{b}\right)$ & $1.24 \times 10^{-2}$ & $3.98 \times 10^{-2}$ \\
\hline Regression coefficient $(r)$ & 0.9971 & 0.9979 \\
\hline
\end{tabular}

${ }^{*}$ Limit of determination as the weight in $\mu \mathrm{g} \mathrm{mL}^{-1}$ of solution, which corresponds to an absorbance of $\mathrm{A}=0.001$ measured in a cuvette of crosssectional area $1 \mathrm{~cm}^{2}$ and $l=1 \mathrm{~cm}$.

${ }^{* *} Y=a+b X$, where $Y$ is the absorbance, $X$ is concentration in $\mu \mathrm{g} \mathrm{mL}^{-1}, a$ is intercept, and $b$ is slope.

are the final chromogen and involve the following chemical species:

$$
\begin{aligned}
& 3 \mathrm{H}_{2} \mathrm{O} \cdot \mathrm{P}_{2} \mathrm{O}_{5} \cdot 13 \mathrm{WO}_{3} \cdot 5 \mathrm{MoO}_{3} \cdot 10 \mathrm{H}_{2} \mathrm{O} \\
& 3 \mathrm{H}_{2} \mathrm{O} \cdot \mathrm{P}_{2} \mathrm{O}_{5} \cdot 14 \mathrm{WO}_{3} \cdot 4 \mathrm{MoO}_{3} \cdot 10 \mathrm{H}_{2} \mathrm{O}
\end{aligned}
$$

INH probably affects reduction of oxygen atoms from tungstate and/or molybdate in the $\mathrm{F}-\mathrm{C}$ reagent by producing one or more possible reduced species which have characteristic intense blue color.

The FFC method involves the redox reaction of INH with ferric chloride, in the presence of potassium ferricyanide, under mild acidic conditions, to produce a blue colour with maximum absorption at $760 \mathrm{~nm}$. The first step in the colour development is the reduction of iron(III) of ferric chloride to iron(II) which subsequently reacts with ferricyanide to form Prussian blue. 


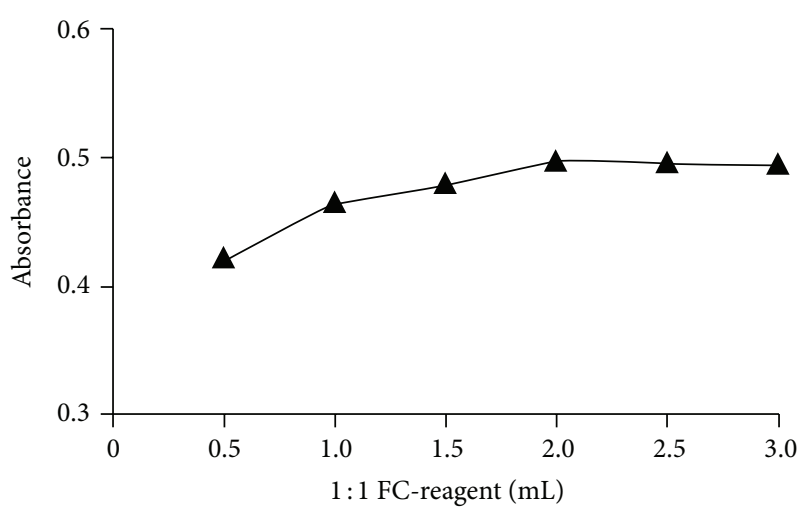

(a)

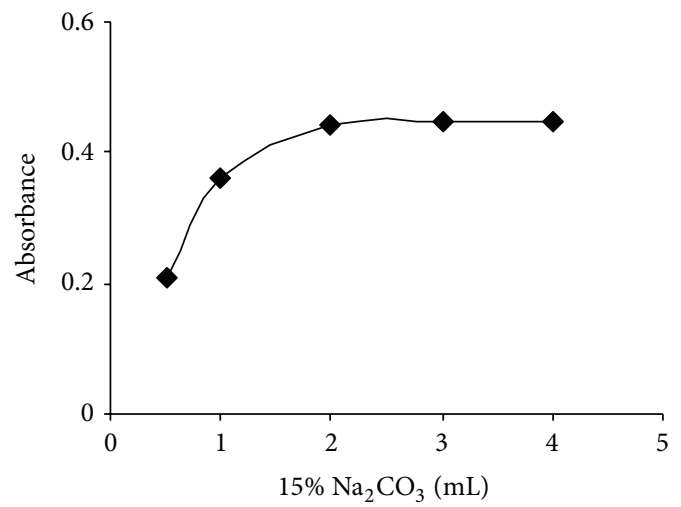

(b)

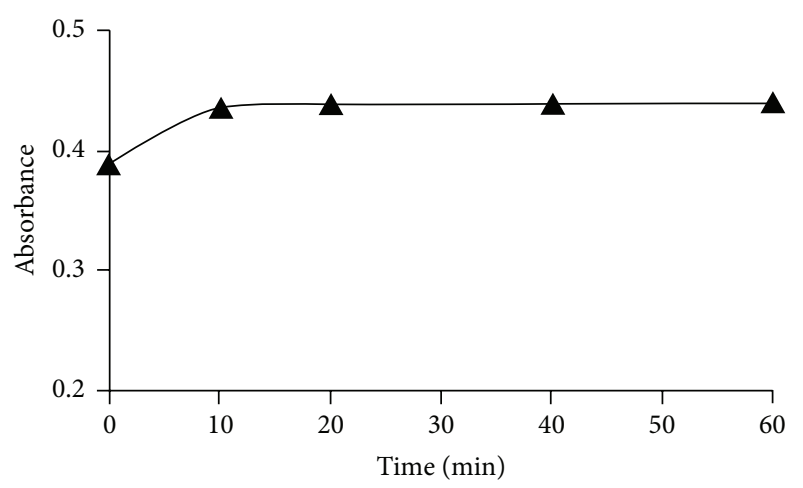

(c)

FIGURE 3: (a) Effect of volumes of F-C reagent $(1: 1)$ on the reaction product with INH $\left(6 \mu \mathrm{g} \mathrm{mL}^{-1}\right)$ in $\mathrm{Na}_{2} \mathrm{CO}_{3}$ solution for method $\mathrm{A}$. (b) Effect of $20 \% \mathrm{Na}_{2} \mathrm{CO}_{3}$ on color formation $\left(6 \mu \mathrm{g} \mathrm{mL}^{-1} \mathrm{INH}\right)$ for method A. (c) Reaction time and stability of colored species for method A $\left(6 \mu \mathrm{g} \mathrm{mL}^{-1} \mathrm{INH}\right)$.

\section{Method Development}

7.1. Spectral Characteristics. The intensely blue colored product (molybdenum-tungsten mixed acid blue in FCR method and Prussian blue in FFC method) formed in both methods exhibited maximum absorption at $760 \mathrm{~nm}$. The absorption spectra of the blue colored products and of the reagent blanks are shown in Figures 2(a) and 2(b).

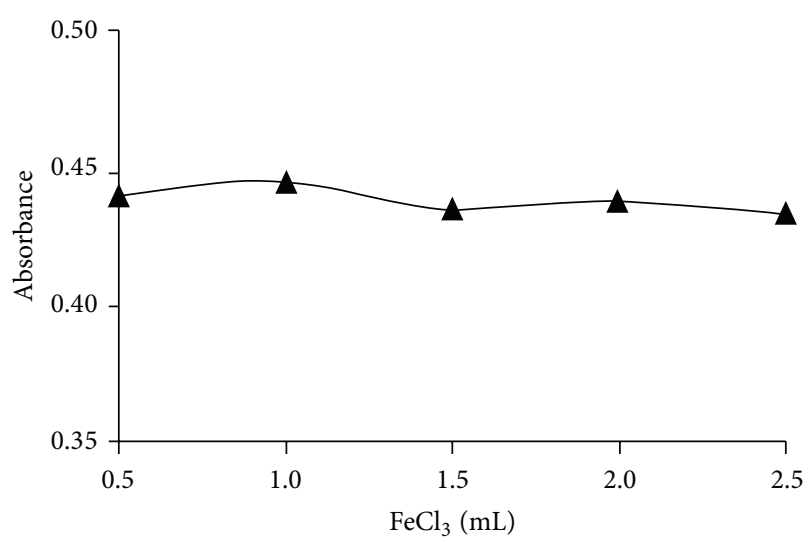

(a)

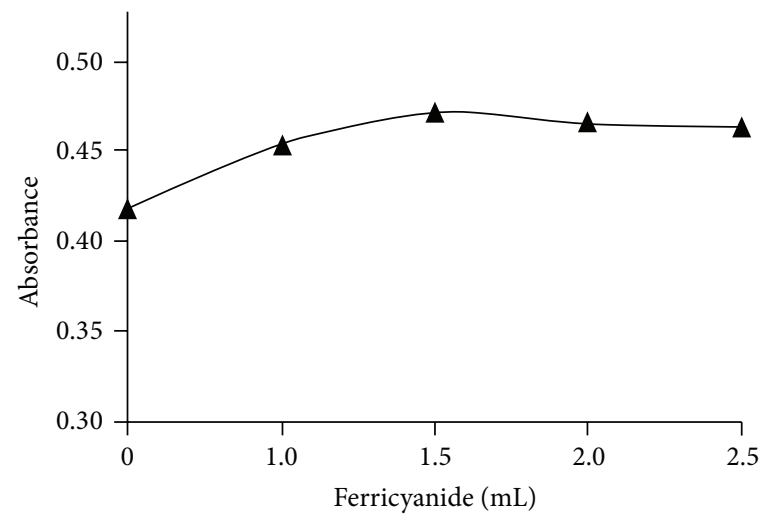

(b)

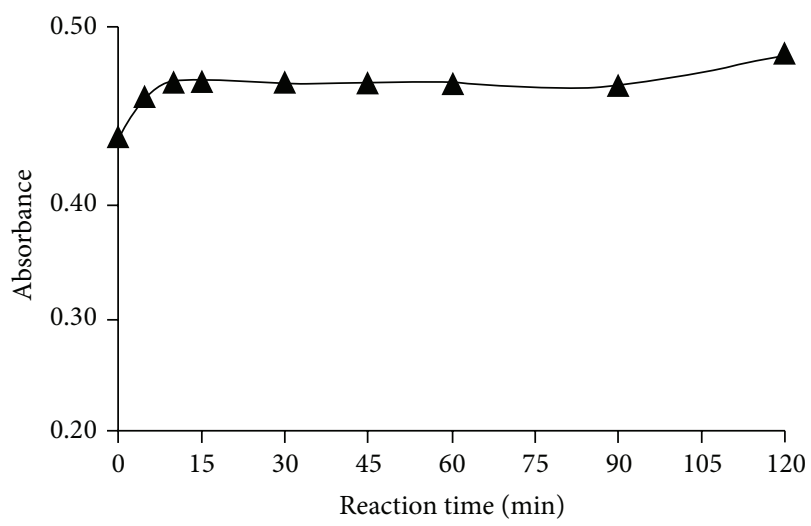

(c)

FIgURE 4: (a) Effect of volume of $\mathrm{FeCl}_{3}$ for method B $\left(1.5 \mu \mathrm{g} \mathrm{mL}^{-1}\right.$ INH). (b) Effect of volume of ferricyanide for method B $\left(1.5 \mu \mathrm{g} \mathrm{mL}^{-1}\right.$ INH). (c) Reaction time and stability of colored species for method $\mathrm{B}\left(1.5 \mu \mathrm{g} \mathrm{mL}^{-1} \mathrm{INH}\right)$.

7.2. Optimization of Experimental Variables. A series of preliminary experiments necessary for rapid and quantitative formation of colored products to achieve the maximum stability and sensitivity were performed. Optimum condition was achieved by varying one parameter at a time while keeping other parameters constant and observing its effect on the absorbance at $760 \mathrm{~nm}$. 
TABLE 2: Evaluation of intraday and interday accuracy and precision.

\begin{tabular}{|c|c|c|c|c|c|c|c|}
\hline \multirow[b]{2}{*}{ Method } & \multirow{2}{*}{ INH Taken $\left(\mu \mathrm{g} \mathrm{mL}^{-1}\right)$} & \multicolumn{3}{|c|}{ Intraday accuracy and precision $(n=7)$} & \multicolumn{3}{|c|}{ Interday accuracy and precision $(n=5)$} \\
\hline & & INH Found ${ }^{\mathrm{a}}\left(\mu \mathrm{g} \mathrm{mL}^{-1}\right)$ & $\begin{array}{c}\mathrm{RSD}^{\mathrm{b}} \\
\%\end{array}$ & $\begin{array}{c}\mathrm{RE}^{\mathrm{c}} \\
\%\end{array}$ & INH found $\left(\mu \mathrm{g} \mathrm{mL}^{-1}\right)$ & $\begin{array}{c}\mathrm{RSD}^{\mathrm{b}} \\
\%\end{array}$ & $\begin{array}{r}\mathrm{RE}^{\mathrm{c}} \\
\%\end{array}$ \\
\hline \multirow{3}{*}{ A } & 3.0 & 2.96 & 1.24 & 0.89 & 3.07 & 2.34 & 2.12 \\
\hline & 6.0 & 6.11 & 1.84 & 1.03 & 6.12 & 2.00 & 2.53 \\
\hline & 9.0 & 9.14 & 1.56 & 1.52 & 9.15 & 1.67 & 2.00 \\
\hline \multirow{3}{*}{ B } & 1.0 & 1.01 & 1.02 & 1.92 & 1.03 & 3.00 & 1.85 \\
\hline & 1.5 & 1.47 & 2.01 & 1.15 & 1.54 & 2.67 & 1.27 \\
\hline & 2.0 & 2.04 & 1.92 & 1.47 & 2.05 & 2.50 & 1.62 \\
\hline
\end{tabular}

${ }^{\mathrm{a}}$ Mean value of 7 determinations; ${ }^{\mathrm{b}}$ relative standard deviation (\%); ${ }^{\mathrm{c}}$ relative error (\%).

TABLE 3: Method robustness and ruggedness expressed as intermediate precision.

\begin{tabular}{|c|c|c|c|c|c|c|}
\hline \multirow[b]{2}{*}{ Method } & \multirow[b]{2}{*}{ Nominal concentration } & \multicolumn{3}{|c|}{ Robustness } & \multicolumn{2}{|c|}{ Ruggedness } \\
\hline & & $\begin{array}{l}\text { Reaction times* } \\
\quad(n=3)\end{array}$ & $\begin{array}{c}\text { Volumes of FC } \\
\text { reagent }^{\#}\end{array}$ & $\begin{array}{c}\text { Volumes } \\
\text { of ferricyanide }\end{array}$ & $\begin{array}{l}\text { Interanalysts } \\
\quad(n=3)\end{array}$ & $\begin{array}{c}\text { Interinstruments } \\
(n=3)\end{array}$ \\
\hline \multirow{3}{*}{ A } & 3.0 & 1.45 & 1.69 & - & 2.20 & 2.32 \\
\hline & 6.0 & 1.72 & 1.35 & - & 1.74 & 1.92 \\
\hline & 9.0 & 2.10 & 1.71 & - & 2.44 & 2.57 \\
\hline \multirow{3}{*}{ B } & 1.0 & 1.72 & - & 1.59 & 1.78 & 2.12 \\
\hline & 1.5 & 1.84 & - & 1.61 & 2.11 & 1.62 \\
\hline & 2.0 & 2.12 & - & 1.72 & 1.07 & 2.54 \\
\hline
\end{tabular}

${ }^{*}$ Reaction times were $10 \pm 2 \mathrm{~min}$ for both methods. ${ }^{*}$ Volumes of FC regent added were $2 \pm 0.2 \mathrm{~mL}$ for method A; volumes of ferricyanide added were $1.5 \pm$ $0.1 \mathrm{~mL}$ for method $\mathrm{B}$.

\subsection{Optimization for FCR Method}

7.3.1. Effect of Concentration of F-C Reagent. Several experiments were carried out to study the influence of $\mathrm{F}-\mathrm{C}$ reagent concentration on the color development and the obtained results are shown in Figure 3(a). It is apparent that 1.0 to $5.0 \mathrm{~mL}$ of reagent gave the maximum color intensity; thus $3.0 \mathrm{~mL}$ of reagent was used throughout the investigation.

7.3.2. Selection of Reaction Medium and Optimization of the Base. To select a suitable medium for the reaction, different aqueous bases such as sodium hydroxide, sodium carbonate or bicarbonate, sodium acetate, and sodium hydrogen phosphate were investigated. Better results were obtained with sodium carbonate. In order to determine the optimum concentration of $\mathrm{Na}_{2} \mathrm{CO}_{3}$, different volumes of $20 \% \mathrm{Na}_{2} \mathrm{CO}_{3}$ solution $(0-5 \mathrm{~mL})$ were attempted at a constant concentration of INH $\left(6 \mu \mathrm{g} \mathrm{mL}^{-1}\right)$ and the results of the observation are shown in Figure 3. It was found that different volumes ranging from 1.0 to $3.0 \mathrm{~mL}$ of $20 \% \mathrm{Na}_{2} \mathrm{CO}_{3}$ were optimum; thus $2.0 \mathrm{~mL}$ was used throughout the work (given in Figure 3(b)).

Maximum color development was obtained in $10 \mathrm{~min}$ after mixing the reactants, and the color was stable for at least $60 \mathrm{~min}$ thereafter (Figure 3(c)). The sequence of order of addition of the reactants had significant effect on the absorbance value. So, the order used in the general procedure should be followed for maximum absorbance.
7.4. Optimization for FFC Method. To optimize the concentrations of ferricyanide and ferric chloride reagents, different volumes of these reagents were used with a fixed concentration of INH. Constant absorbance was found with $1.0 \mathrm{~mL}$ of $0.5 \mathrm{M} \mathrm{FeCl}_{3}$ and $1.5 \mathrm{~mL}$ of $500 \mu \mathrm{g} \mathrm{mL}^{-1}$ ferricyanide solutions, as shown in Figures 4(a) and 4(b).

Colour development was complete in $10 \mathrm{~min}$ and stable for the next $90 \mathrm{~min}$ (Figure 4(c)). Different results were obtained when different order of addition of reactants was followed. The order of addition of reactants followed in the recommended procedure resulted in rapid color formation with maximum sensitivity and stability.

\section{Method Validation}

8.1. Linearity, Sensitivity, Limits of Detection, and Quantification. A linear correlation was found between absorbance at $\lambda_{\max }$ and concentration of INH in the ranges given in Table 1. Regression analysis of the Beer's law data using the method of least squares was made to evaluate the slope $(b)$, intercept $(a)$, and correlation coefficient $(r)$ for each system and the analytical results obtained from these investigations are presented in Table 1. The optical characteristics such as Beer's law limits, molar absorptivity, and Sandell sensitivity values are also given in Table 1 . The high values of $\varepsilon$ and low values of Sandell sensitivity and LOD indicate the high sensitivity of the proposed methods. 
TABLE 4: Results of analysis of tablets by the proposed methods.

\begin{tabular}{|c|c|c|c|c|}
\hline \multirow{3}{*}{ Tablets analyzed } & \multirow{3}{*}{ Label claim (mg/tablet) } & \multicolumn{3}{|c|}{ Found* (percent of label claim \pm SD) } \\
\hline & & \multirow{2}{*}{ Official method } & \multicolumn{2}{|c|}{ Proposed methods } \\
\hline & & & Method A & Method B \\
\hline \multirow{3}{*}{ Iskin-300 } & & & $101.5 \pm 1.16$ & $101.2 \pm 0.92$ \\
\hline & 300 & $99.86 \pm 1.36$ & $t=2.06$ & $t=1.83$ \\
\hline & & & $F=1.37$ & $F=2.19$ \\
\hline
\end{tabular}

${ }^{*}$ Mean value of five determinations.

Tabulated $t$-value at the $95 \%$ confidence level is 2.77 .

Tabulated $F$-value at the $95 \%$ confidence level is 6.39 .

TABLE 5: Results of recovery study via standard addition method with tablet.

\begin{tabular}{lccccc}
\hline Method & Tablets studied & INH in tablet $\mu \mathrm{g} \mathrm{mL}^{-1}$ & Pure INH Added $\mu \mathrm{gLL}^{-1}$ & Total Found $\mu \mathrm{gL}^{-1}$ & $\begin{array}{c}\text { Pure INH recovered }^{*} \\
\text { percent } \pm \mathrm{SD}\end{array}$ \\
\hline \multirow{3}{*}{ A } & & 2.96 & 1.5 & 4.41 & $99.28 \pm 2.03$ \\
& Isokin-300 & 2.96 & 3.0 & 6.01 & $100.9 \pm 3.12$ \\
& & 2.96 & 4.5 & 7.56 & $101.3 \pm 2.99$ \\
\hline \multirow{3}{*}{ B } & & 1.01 & 0.5 & 2.04 & $99.85 \pm 2.25$ \\
& Isokin-300 & 1.01 & 1.0 & 2.55 & $101.3 \pm 2.32$ \\
\hline
\end{tabular}

${ }^{*}$ Mean value of three determinations.

8.2. Intraday and Interday Precision and Accuracy. The precision and accuracy of the proposed method were studied by repeating the experiment seven times within the day to determine the repeatability (intraday precision) and five times on different days to determine the intermediate precision (interday precision). The assay was performed for three levels of analyte in this method. The results of this study are summarized in Table 2 . The percentage relative standard deviation (\%RSD) values were $\leq 2.01 \%$ (intraday) and $\leq 3.00 \%$ (interday) indicating good precision of the method. Accuracy was evaluated as percentage relative error $(\% \mathrm{RE})$ between the measured mean concentrations and taken concentrations of $\mathrm{INH}$, and it was $\leq 2.53 \%$ demonstrating the high accuracy of the proposed method.

8.3. Selectivity. A selective study was performed to determine the effect of matrix on the absorbance by analyzing the placebo blank. In the analysis of placebo blank solution the absorbance in each case was equal to the absorbance of blank which revealed no interference. To assess the role of the inactive ingredients on the assay of INH, the general procedure was applied on the synthetic mixture extract by taking three different concentrations of INH within the range. The percentage recovery values were in the range 96.3$102.3 \%$ and $95.4-101.8 \%$ with RSD $<4 \%$ indicating clearly the noninterference from the inactive ingredients in the assay of INH.

8.4. Robustness and Ruggedness. The robustness of the method was evaluated by making small incremental changes in the volume of reagent and reaction time, and the effects of the changes were studied by measuring the absorbance of the colored product. The changes had negligible influence on the results as revealed by small intermediate precision values expressed as $\%$ RSD $(\leq 2.54 \%)$. Method ruggedness was demonstrated having the analysis done by three analysts and also by a single analyst performing analysis on three different instruments in the same laboratory. Intermediate precision values (\%RSD) in both instances indicated acceptable ruggedness. These results are presented in Table 3.

8.5. Application to Tablets. The proposed methods were applied to the quantification of INH in commercial tablets. The tablets were assayed by the official BP method [2], which describes titration of the drug with potassium bromate in presence of potassium bromide using methyl red indicator. The results obtained by the proposed methods agree well with the claim and also are in agreement with those of the official method. Statistical analysis of the results did not detect any significant difference between the performance of the proposed method and reference method with respect to accuracy and precision as revealed by the Student's $t$-value and variance ratio $F$-value. The results of assay are given in Table 4.

8.6. Recovery Study. To further assess the accuracy of the method, recovery experiment was performed by applying the standard-addition technique. The recovery was assessed by determining the agreement between the measured standard concentration and added known concentration to the sample. The test was done by spiking the preanalyzed tablet INH with pure INH at three different levels $(50,100$, and 150\%) of the content present in the preparation and the total was found by the proposed method. Each test was repeated three times. The recovery percentage values ranged between 99.28 and $101.7 \%$ with standard deviation in the range $0.99-1.32 \%$. Closeness 


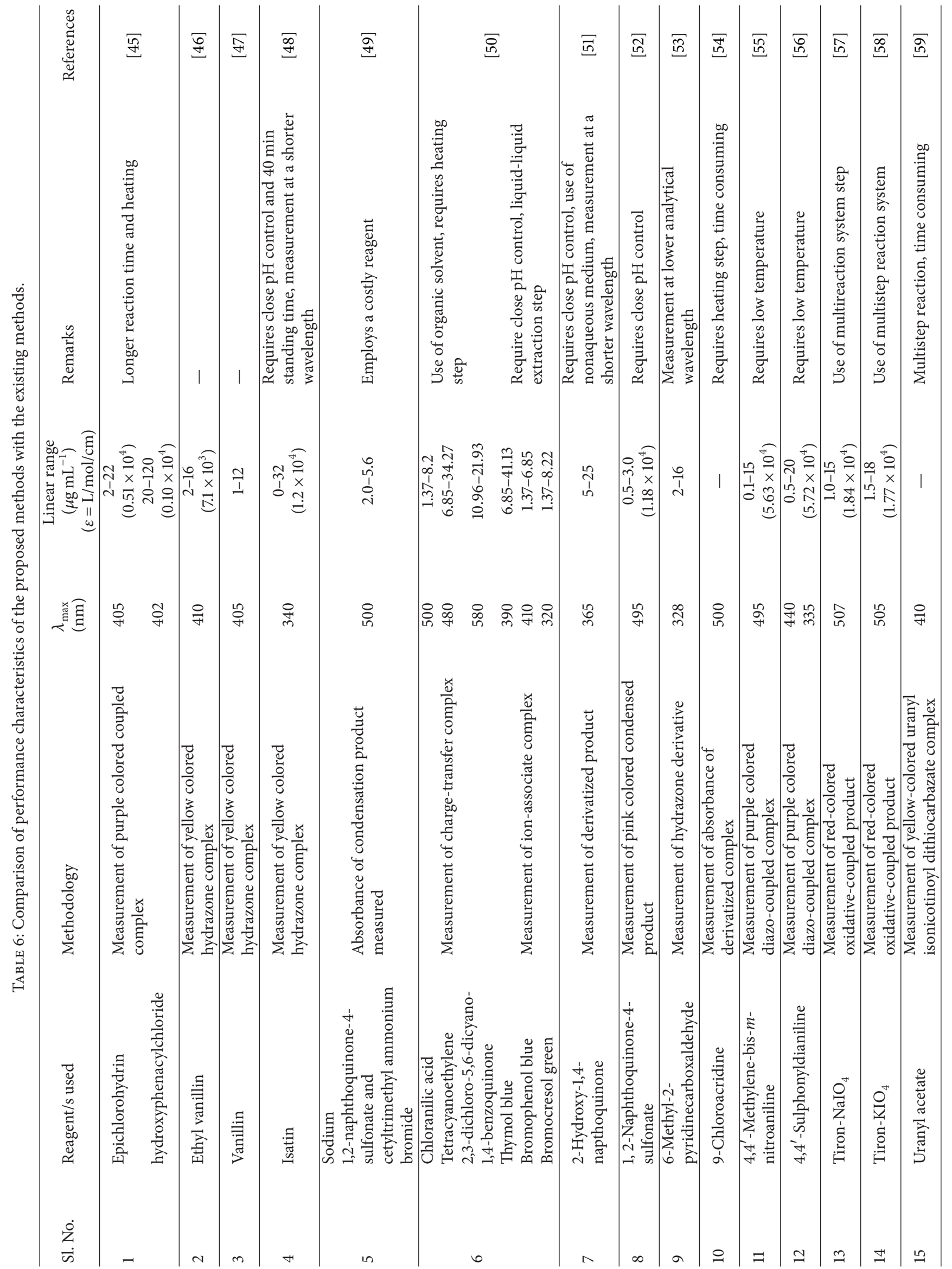




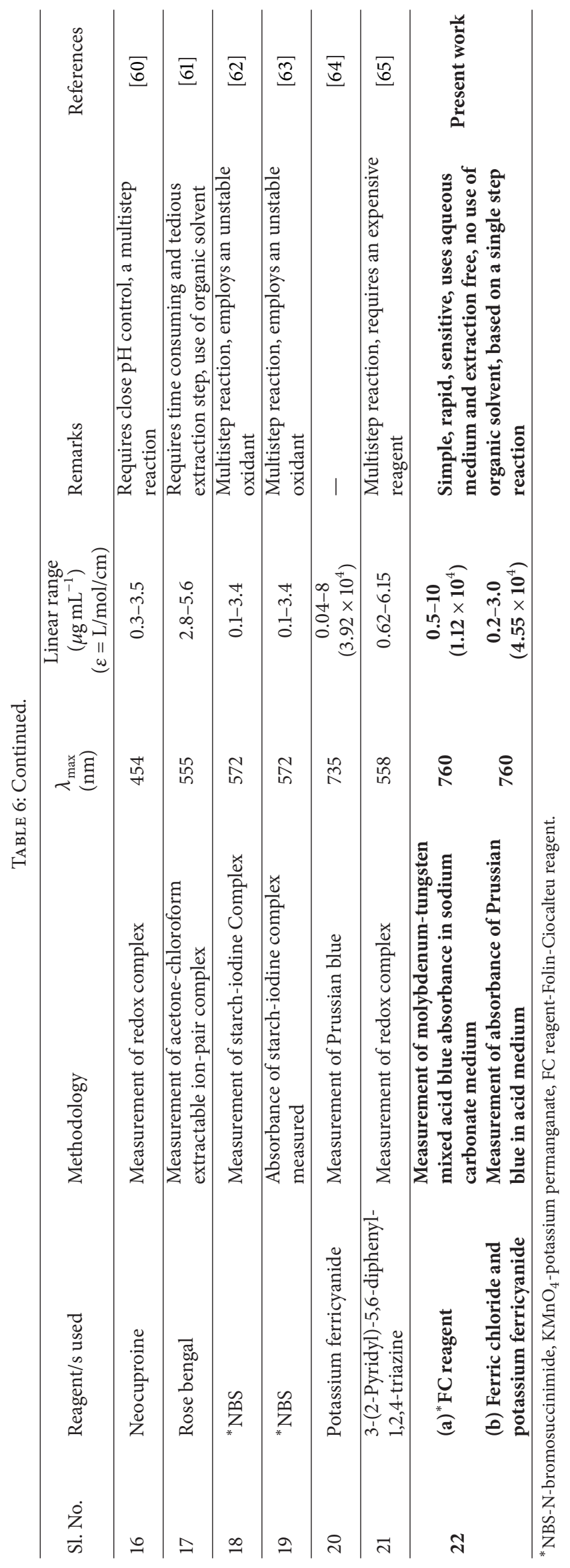


of the results to $100 \%$ showed the fairly good accuracy of the method. The results are shown in Table 5.

\section{Conclusion}

Two simple, rapid, selective, and sensitive methods have been proposed for the assay of INH in bulk drugs and in tablets. The methods are based on the well-characterized and established redox and complexation reactions and use very common and inexpensive chemicals and easily accessible instrument. The procedures described here are easily carried out and much simpler than the reported methods for INH (Table 6) but have been demonstrated to be more sensitive in terms of linear dynamic range and sensitivity parameters. The methods were applied successfully to the assay of INH in tablets without interferences from the common excipients. The proposed methods are suitable for isoniazid determination in bulk drug and pharmaceuticals; hence these methods can be used in quality control laboratories.

\section{Conflict of Interests}

The authors declare that there is no conflict of interests regarding the publication of this paper.

\section{Acknowledgments}

The authors wish to thank the quality control manager, Cipla Ltd., Bangalore, India, for gifting pure isoniazid and the authorities of the University of Mysore, Mysore, for permission and facilities.

\section{References}

[1] Indian Pharmacopoea Vol. I, The controller of Publications. Govt. of India, New Delhi, India, 4th edition, 1996.

[2] British Pharmacopoeia, Volume I and II, Her Majesty's Stationery Office, London, UK, 2009.

[3] The United States Pharmacopoeia, XXIV Revision, The National Formulary XIX Rockville, USP Convention, 2000.

[4] P. Nagendra, H. S. Yathirajan, K. N. Mohana, and K. S. Rangappa, "Oxidation of isoniazid and glutathione with bromamine-T," Journal of the Indian Chemical Society, vol. 79, no. 1, pp. 75-78, 2002.

[5] C. R. Raju, H. S. Yathirajan, K. S. Rangappa, K. N. Mohana, and K. M. L. Rai, "Oxidimetric determination of isoniazid and amino acids with bromamine-B in buffer medium," Oxidation Communications, vol. 24, no. 3, pp. 393-399, 2001.

[6] B. M. Mohan, H. S. Yathirajan, R. Rangaswamy, and J. Jayarama, "Determination of ascorbic acid and isoniazid with nbromosuccinimide," Indian Journal of Pharmaceutical Sciences, vol. 46, no. 4, pp. 156-158, 1984.

[7] A. Das and K. S. Boparai, "Titration of thiacetazone and isoniazid with sodium methoxide in non-aqueous medium," Talanta, vol. 29, no. 1, pp. 57-60, 1982.

[8] U. P. Azad and V. Ganesan, "Efficient electrocatalytic oxidation and selective determination of isoniazid by $\mathrm{Fe}(\mathrm{tmphen})_{3}^{2+}$ exchanged Nafion-modified electrode," Journal of Solid State Electrochemistry, vol. 16, no. 9, pp. 2907-2911, 2012.
[9] S. Shahrokhian and E. Asadian, "Simultaneous voltammetric determination of ascorbic acid, acetaminophen and isoniazid using thionine immobilized multi-walled carbon nanotube modified carbon paste electrode," Electrochimica Acta, vol. 55, no. 3, pp. 666-672, 2010.

[10] G. Yang, C. Wang, R. Zhang, C. Wang, Q. Qu, and X. Hu, "Poly(amidosulfonic acid) modified glassy carbon electrode for determination of isoniazid in pharmaceuticals," Bioelectrochemistry, vol. 73, no. 1, pp. 37-42, 2008.

[11] Z.-N. Gao, X.-X. Han, H.-Q. Yao, B. Liang, and W.-Y. Liu, "Electrochemical oxidation of isoniazid catalyzed by (FcM)TMA at the platinum electrode and its practical analytical application," Analytical and Bioanalytical Chemistry, vol. 385, no. 7, pp. 13241329, 2006.

[12] M. R. Majidi, A. Jouyban, and K. Asadpour-Zeynali, "Voltammetric behavior and determination of isoniazid in pharmaceuticals by using overoxidized polypyrrole glassy carbon modified electrode," Journal of Electroanalytical Chemistry, vol. 589, no. 1, pp. 32-37, 2006.

[13] T. Wahdan, "Voltammetric method for the simultaneous determination of rifampicin and isoniazid in pharmaceutical formulations," Chemia Analityczna, vol. 50, no. 2, pp. 457-464, 2005.

[14] I. Pasáková, M. Gladziszová, J. Charvátová, J. Stariat, J. Klimeš, and P. Kovaříková, "Use of different stationary phases for separation of isoniazid, its metabolites and vitamin B6 forms," Journal of Separation Science, vol. 34, no. 12, pp. 1357-1365, 2011.

[15] M. Gajendiran and M. M. Abdul Kamal Nazer, "Potentiometric back titration of isoniazid in pharmaceutical dosage forms using copper based mercury film electrode," Journal of the Korean Chemical Society, vol. 55, no. 4, pp. 620-625, 2011.

[16] L. Lakshmi, "Potentiotitrimetric determination of isoniazid using twin copper based mercury film electrode," Asian Journal of Chemistry, vol. 22, no. 8, pp. 6067-6076, 2010.

[17] P. Riyazuddin and M. M. Abdul Kamal Nazer, "Indirect potentiometric titration of isoniazid in pharmaceutical dosage forms using a copper based mercury film electrode," Indian Journal of Pharmaceutical Sciences, vol. 60, no. 3, pp. 158-161, 1998.

[18] M. A. Koupparis and T. P. Hadjiioannou, "Indirect potentiometric determination of hydrazine, isoniazid, sulphide and thiosulphate with a chloramine-T ion-selective electrode," Talanta, vol. 25, no. 8, pp. 477-480, 1978.

[19] P. V. Krishna Rao and G. Bala Bhaskara Rao, "A potentiometric procedure for the assay of isonicotinic acid hydrazide (isoniazid)," The Analyst, vol. 96, no. 147, pp. 712-715, 1971.

[20] W. C. Chen, B. Unnikrishnan, and S. M. Chen, "Electrochemical oxidation and amperometric determination of isoniazid at functionalized multiwalled carbon nanotube modified electrode," International Journal of Electrochemical Science, vol. 7, no. 10, pp. 9138-9149, 2012.

[21] M. S. M. Quintino and L. Angnes, "Fast BIA-amperometric determination of isoniazid in tablets," Journal of Pharmaceutical and Biomedical Analysis, vol. 42, no. 3, pp. 400-404, 2006.

[22] T. Hossein, H. Yahya, and T. Afsaneh, "A selective and simple method for isoniazid spectrofluorimetric determination based on the oxidation by cerium(IV)," Asian Journal of Biochemical and Pharmaceutical Research, vol. 1, no. 2, pp. 712-718, 2011.

[23] J. A. García Bautista, J. V. García Mateo, and J. Martínez Calatayud, "Spectrofluorimetric determination of iproniazid and isoniazid in a FIA system provided with a solid-phase reactor," Analytical Letters, vol. 31, no. 7, pp. 1209-1218, 1998. 
[24] W. Bowan, W. Zhihua, X. Zhonghua et al., "A novel molecularty imprinted electrochemiluminescence sensor for isoniazid detection," The Analyst, vol. 137, no. 16, pp. 3644-3652, 2012.

[25] J. Xi, B. Shi, X. Ai, and Z. He, "Chemiluminescence detection of isoniazid using $\mathrm{Ru}(\mathrm{phen})_{3}^{2+}$-isoniazid-Ce(IV) system," Journal of Pharmaceutical and Biomedical Analysis, vol. 36, no. 1, pp. 237-241, 2004.

[26] A. Safavi, M. A. Karimi, and M. R. H. Nezhad, "Flow injection determination of isoniazid using N-bromosuccinimide- and Nchlorosuccinimide-luminol chemiluminescence systems," Journal of Pharmaceutical and Biomedical Analysis, vol. 30, no. 5, pp. 1499-1506, 2003.

[27] S. Zhang and H. Li, "Flow-injection chemiluminescence sensor for the determination of isoniazid," Analytica Chimica Acta, vol. 444, no. 2, pp. 287-294, 2001.

[28] X. Zheng, Z. Guo, and Z. Zhang, "Flow-injection electrogenerated chemiluminescence determination of isoniazid using luminol," Analytical Sciences, vol. 17, no. 9, pp. 1095-1099, 2001.

[29] Y. Huang and Z. Zhang, "Flow injection chemiluminescent analysis of isoniazid by direct hexacyanoferrate(III) oxidation," Analytical Letters, vol. 34, no. 10, pp. 1703-1710, 2001.

[30] Y. Huang, Z. Zhang, D. Zhang, and J. Lv, "A flow injection chemiluminescence system for the determination of isoniazid," Fresenius' Journal of Analytical Chemistry, vol. 368, no. 4, pp. 429-431, 2000.

[31] B. Li, Z. Zhang, X. Zheng, and C. Xu, "Flow injection chemiluminescence determination of isoniazid using on-line electrogenerated manganese(III) as oxidant," Microchemical Journal, vol. 63, no. 3, pp. 374-380, 1999.

[32] X. Zheng and Z. Zhang, "Flow-injection chemiluminescence determination of isoniazid using on-line electrogenerated $\mathrm{BrO}$ as an oxidant," The Analyst, vol. 124, no. 5, pp. 763-766, 1999.

[33] J. Huang, C. Zhang, and Z. Zhang, "Flow injection chemiluminescence determination of isoniazid with electrogenerated hypochlorite," Fresenius' Journal of Analytical Chemistry, vol. 363, no. 1, pp. 126-128, 1999.

[34] J. Ayyappan, P. Umapathi, and S. Darlin Quine, "Development and validation of a stability indicating high-performance liquid chromatography (HPLC) method for the estimation of isoniazid and its related substances in fixed dose combination of isoniazid and ethambutol hydrochloride tablets," African Journal of Pharmacy and Pharmacology, vol. 5, no. 12, pp. 15131521, 2011.

[35] S. Gunasekaran and E. Sailatha, "Estimation of pyrazinamide, isoniazid and rifampicin in pharmaceutical formulations by high performance liquid chromatography method," Asian Journal of Chemistry, vol. 21, no. 5, pp. 3561-3566, 2009.

[36] B. D. Glass, S. Agatonovic-Kustrin, Y.-J. Chen, and M. H. Wisch, "Optimization of a stability-indicating HPLC method for the simultaneous determination of rifampicin, isoniazid, and pyrazinamide in a fixed-dose combination using artificial neural networks," Journal of Chromatographic Science, vol. 45, no. 1, pp. 38-44, 2007.

[37] V. D. Gupta and A. Sood, "Chemical stability of isoniazid in an oral liquid dosage form," International Journal of Pharmacy and Compounding, vol. 9, no. 2, pp. 165-166, 2005.

[38] M. Y. Khuhawar and L. A. Zardari, "Ethyl chloroformate as a derivatizing reagent for the gas chromatographic determination of isoniazid and hydrazine in pharmaceutical preparations," Analytical Sciences, vol. 24, no. 11, pp. 1493-1496, 2008.

[39] M. Y. Khuhawar, L. A. Zardari, and A. J. Laghari, “Capillary gas chromatographic determination of isoniazid in pharmaceutical preparation by pre-column derivatization with acetylacetone," Asian Journal of Chemistry, vol. 20, no. 8, pp. 5997-6006, 2008.

[40] M. Y. Khuhawar and L. A. Zardari, "Capillary gas chromatographic determination of isoniazid in pharmaceutical preparations and blood precolumn derivazation with trifluoroacetylacetone," Journal of Food and Drug Analysis, vol. 14, no. 4, pp. 323-328, 2006.

[41] H. Bhutani, S. Singh, S. Vir et al., "LC and LC-MS study of stress decomposition behaviour of isoniazid and establishment of validated stability-indicating assay method," Journal of Pharmaceutical and Biomedical Analysis, vol. 43, no. 4, pp. 1213-1220, 2007.

[42] Y. Liu, Z. Fu, and L. Wang, "Capillary electrophoresis analysis of isoniazid using luminol-periodate potassium chemiluminescence system," Luminescence, vol. 26, no. 6, pp. 397-402, 2011.

[43] X. Zhang, Y. Xuan, A. Sun, Y. Lv, and X. Hou, "Simultaneous determination of isoniazid and $p$-aminosalicylic acid by capillary electrophoresis using chemiluminescence detection," Luminescence, vol. 24, no. 4, pp. 243-249, 2009.

[44] R. Driouich, T. Takayanagi, M. Mitsuko, O. Oshima, and S. Motomizu, "Investigation of salicylaldehyde-5-sulfonate as a precolumn derivatizing agent for the determination of $n$ alkane diamines, lysine, diaminopimelic acid, and isoniazid by capillary zone electrophoresis," Journal of Pharmaceutical and Biomedical Analysis, vol. 30, no. 5, pp. 1523-1530, 2003.

[45] D. N. Shetty, N. Badiyadka, and S. Samshuddin, "Novel reagents for the spectrophotometric determination of isoniazid," ISRN Spectroscopy, vol. 2012, Article ID 869493, 5 pages, 2012.

[46] R. Kashyap, E. V. S. Subrahmanyam, and A. R. Sharbarayam, "Development and validation of new colorimetric method for the estimation of isoniazid in bulk and dosage form," International Journal of Pharmacy and Pharmaceutical Sciences, vol. 4, no. 3, pp. 688-695, 2012.

[47] E. F. Oga, "Spectrophotometric determination of isoniazid in pure and pharmaceutical formulations using vanillin," International Journal of Pharmacy and Pharmaceutical Sciences, vol. 2, no. 1, pp. 55-58, 2010.

[48] M. N. Abbas and A. M. A. Homoda, "Spectrophotometric determination of isoniazid in presence of rifampicin in some pharmaceutical preparations and urine, using isatin as a reagent," Egyptian Journal of Chemistry, vol. 46, no. 1, pp. 57-69, 2003.

[49] P. Nagaraja, K. C. Srinivasa Murthy, and H. S. Yathirajan, "Spectrophotometric determination of isoniazid with sodium 1,2naphthoquinone-4-sulphonate and cetyltrimethyl ammonium bromide," Talanta, vol. 43, no. 7, pp. 1075-1080, 1996.

[50] M. S. Kamel, "Spectrophotometric determination of isoniazid in pure form and pharmaceutical preparation," World Journal of Chemistry, vol. 3, no. 1, pp. 11-16, 2008.

[51] F. M. A. Rind, M. Y. Khuhawar, K. F. Almani, and A. D. Rajpar, "Spectrophotometric determination of isoniazid in dosage forms by derivatization," Pakistan Journal of Analytical Chemistry, vol. 6, no. 2, pp. 84-88, 2005.

[52] Q.-M. Li and Z.-J. Yang, "Spectrophotometric study of isoniazid by using 1,2-naphthoquinone-4-sulfonic acid sodium as the chemical derivative chromogenic reagent," Journal of the Chinese Chemical Society, vol. 53, no. 2, pp. 383-389, 2006.

[53] M. Y. Khuhawar, F. M. A. Rind, and K. F. Almani, "Spectrophotometric determination of isoniazid using 6-methyl-2-pyridine carboxaldehyde as a derivatizing reagent," Journal of Chemical Society of Pakistan, vol. 20, no. 4, pp. 260-263, 1998. 
[54] J. T. Stewart and D. A. Settle, "Colorimetric determination of isoniazid with 9 chloroacridine," Journal of Pharmaceutical Sciences, vol. 64, no. 8, pp. 1403-1405, 1975.

[55] G. K. Naidu, K. Suvardhan, K. S. Kumar, D. Rekha, B. S. Sastry, and P. Chiranjeevi, "Simple sensitive spectrophotometric determination of isoniazid and ritodrine hydrochloride," Journal of Analytical Chemistry, vol. 60, no. 9, pp. 822-827, 2005.

[56] P. Nagaraja, K. Sunitha, R. Vasantha, and H. Yathirajan, "Novel method for the spectrophotometric determination of isoniazid and ritodrine hydrochloride," Turkish Journal of Chemistry, vol. 26, no. 5, pp. 743-750, 2002.

[57] B. G. Gowda, M. B. Melwanki, K. C. Ramesh, and J. Keshavayya, "Spectrophotometric determination of isoniazid in pure and pharmaceutical formulations," Indian Journal of Pharmaceutical Sciences, vol. 65, no. 1, pp. 86-90, 2005.

[58] B. G. Gowda, M. B. Melwanki, J. Seetharamappa, and K. C. Srinivasa Murthy, "Spectrophotometric determination of isoniazid in pure and pharmaceutical formulations," Analytical Sciences, vol. 18, no. 7, pp. 839-841, 2002.

[59] S. B. Kalia, G. Kaushal, and B. C. Verma, "Spectrophotometric method for the determination of isoniazid," Journal of the Indian Chemical Society, vol. 83, no. 1, pp. 83-84, 2006.

[60] A. Safavi, M. A. Karimi, M. R. Hormozi Nezhad, R. Kamali, and N. Saghir, "Sensitive indirect spectrophotometric determination of isoniazid," Spectrochimica Acta A: Molecular and Biomolecular Spectroscopy, vol. 60, no. 4, pp. 765-769, 2004.

[61] M. S. Amer, Z. El-Sherif, and M. M. Amer, "Spectrophotometric determination of isoniazid, nalidixic acid and flumequine through ternary complex-formation with $\mathrm{Cd}(\mathrm{II})$ and rose Bengal," Egyptian Journal of Pharmaceutical Sciences, vol. 35, no. 1-6, pp. 627-642, 1994.

[62] M. M. A. Diab, B. N. Barsoum, M. S. Kamel, and S. Z. ElKhateeb, "Spectrophotometric determination of isoniazid and rifampicin," Bulletin of Faculty of Pharmacy (Assuit Univ.), vol. 46, no. 3, pp. 103-113, 2008.

[63] N. B. Barsoum, M. S. Kamel, and M. M. A. Diab, "Spectrophotometric determination of isoniazid and rifampicin from pharmaceutical preparations and biological fluids," Research Journal of Agricultural and Biological Sciences, vol. 4, no. 5, pp. 471-484, 2008.

[64] H. Zhang, L. Wu, Q. Li, and X. Du, "Determination of isoniazid among pharmaceutical samples and the patients' saliva samples by using potassium ferricyanide as spectroscopic probe reagent," Analytica Chimica Acta, vol. 628, no. 1, pp. 67-72, 2008.

[65] A. Safavi and M. Bagheri, "Design of an optical sensor for indirect determination of isoniazid," Spectrochimica Acta A, vol. 70, no. 4, pp. 735-739, 2008.

[66] K. Basavaiah and H. C. Prameela, "Spectrophotometric determination of diclofenac sodium using Folin-Ciocalteu reagent in bulk drug and in dosage form," Eastern Pharmacist, vol. 1, pp. 61-63, 2002.

[67] T. K. Murthy, G. D. Sankar, and Y. S. Rao, "Visible spectrophotometric methods for the determination oftrimetazidine dihydrochloride in pharmaceutical formulations," Indian Drugs, vol. 39, no. 4, pp. 230-233, 2002.

[68] K. Basavaiah and H. C. Prameela, "Simple spectrophotometric determination of acyclovir in bulk drug and formulations," IL Farmaco, vol. 57, no. 6, pp. 443-449, 2002.

[69] C. S. P. Sastry and J. S. V. M. Lingeswara Rao, "Spectrophotometric methods for the determination of methotrexate in pharmaceutical formulations," Analytical Letters, vol. 29, no. 10, pp. 1763-1778, 1996.
[70] C. S. P. Sastry, P. Y. Naidu, and S. S. N. Murty, "Spectrophotometric methods for the determination of omeprazole in bulk form and pharmaceutical formulations," Talanta, vol. 44, no. 7, pp. 1211-1217, 1997.

[71] C. S. P. Sastry, A. Sailaja, T. T. Rao, and D. M. Krishna, “Three simple spectrophotometric methods for the determination of sulphinpyrazone," Talanta, vol. 39, no. 6, pp. 709-713, 1992.

[72] S. Raghuveer, A. B. Avadhanulu, and A. R. Pantulu, "Spectrophotometric determination of gliclazide in its pharmaceutical dosage forms using Folin-Ciocalteu reagent," Eastern Pharmacist, vol. 35, no. 1, pp. 129-130, 1992.

[73] O. Folin and V. Ciocalteu, "On tyrosine and tryptophane determinations in proteins," Journal of Biological Chemistry, vol. 73, no. 1, pp. 627-650, 1927.

[74] A. V. Prasad, P. A. Devi, C. S. P. Sastry, and U. V. Prasad, "Assay of minocycline and tylosin using Folin-Ciocalteu reagent," Eastern Pharmacist, vol. 2, no. 2, pp. 67-68, 2003.

[75] International Conference on Harmonization of technical requirements for registration of pharmaceuticals for human use, ICH harmonized tripartite guideline, validation of analytical procedures: text and methodology Q2 (R 1), complementary guideline on methodology dated 06 November 1996, London, UK, November 2005. 

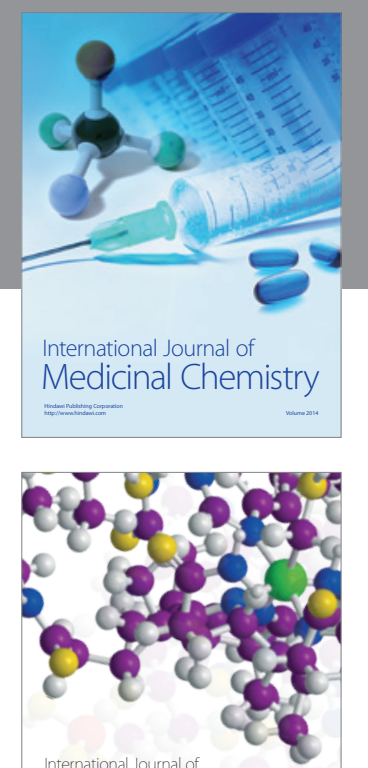

\section{Carbohydrate} Chemistry

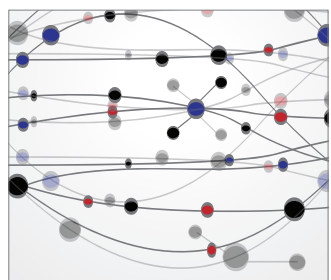

The Scientific World Journal
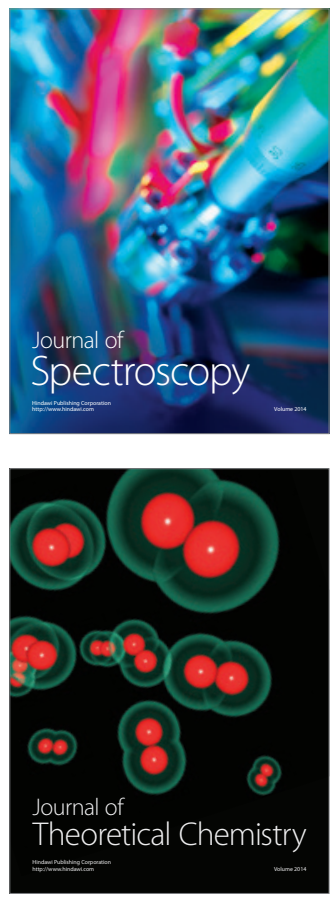
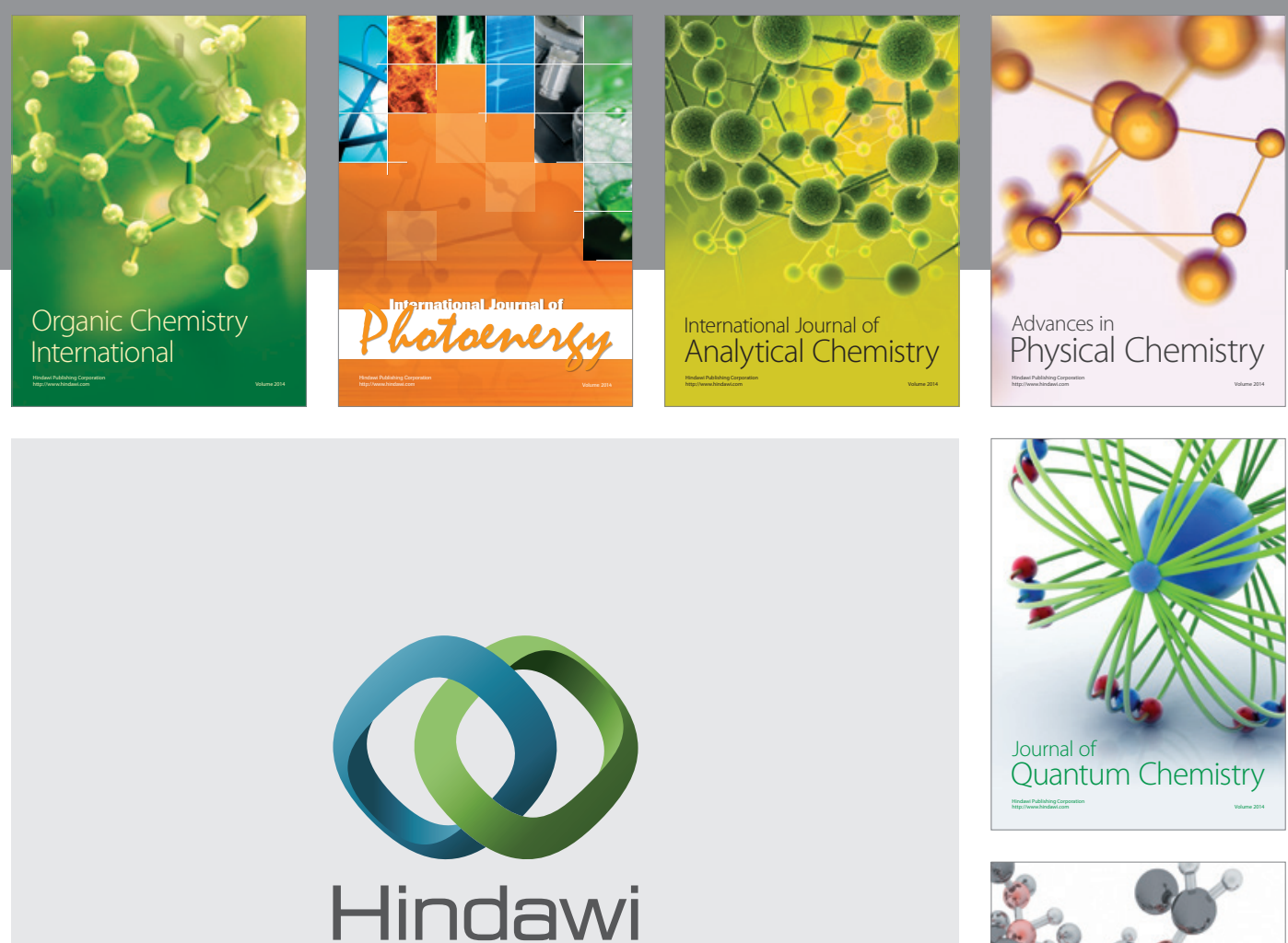

Submit your manuscripts at

http://www.hindawi.com

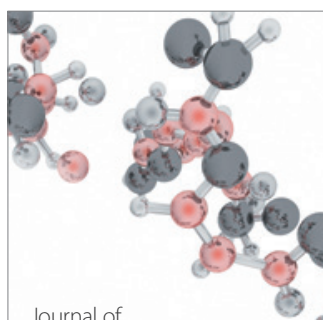

Analytical Methods

in Chemistry

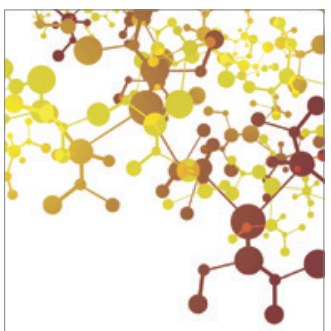

Journal of

Applied Chemistry

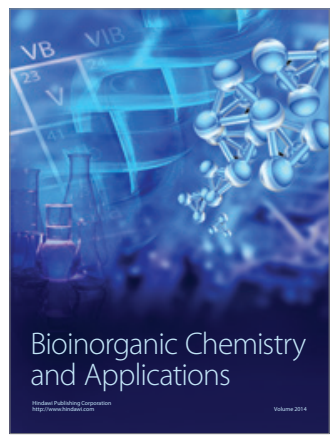

Inorganic Chemistry
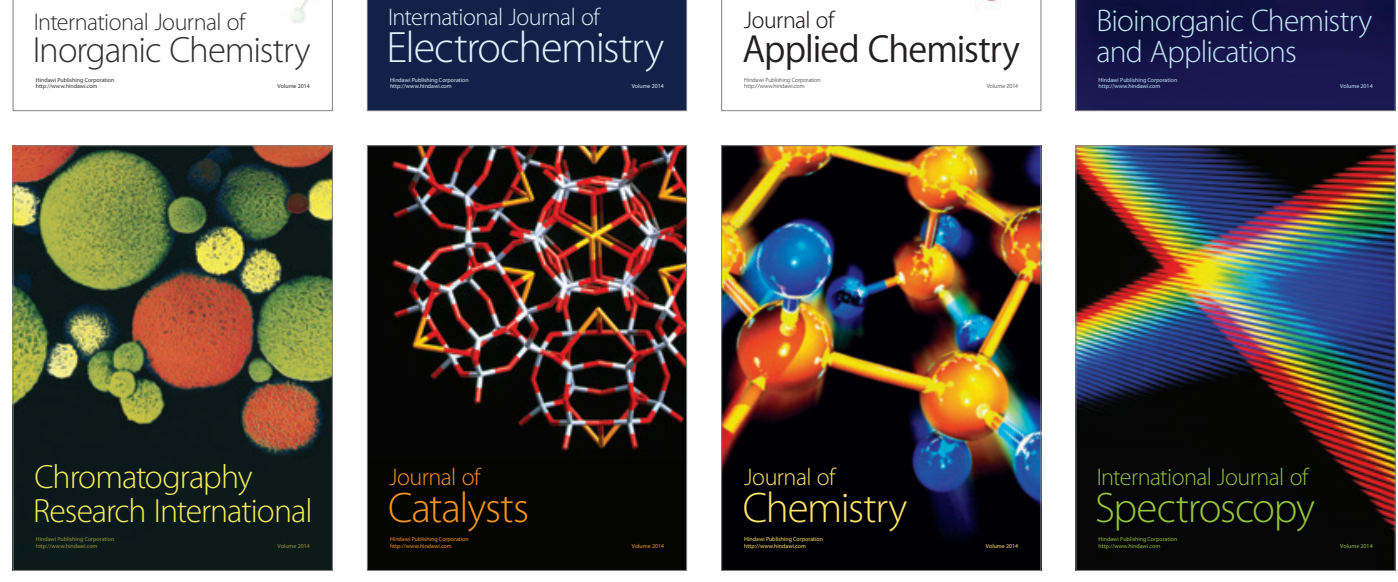